\title{
O DIREITO AMBIENTAL E A GEOGRAFIA NO PONTAL DO PARANAPANEMA: MARABÁ PAULISTA E PRESIDENTE VENCESLAU-SP.
}

\author{
Lucas Cesar Bonato Rós, Adriel Prado de Oliveira, Maria Helena Pereira Mirante, Fabio Ferreira \\ Morong
}

Universidade do Oeste Paulista - UNOESTE, curso de Direito, Presidente Prudente, SP. E-mail:

lucas.b_ros@hotmail.com; adriel_prado@hotmail.com; madelainy1361@hotmail.com; fabiomorong@hotmail.com

\begin{abstract}
RESUMO
A temática sobre o Direito Ambiental e a Geografia do Pontal do Paranapanema - SP está aflorada em uma mesma posse de desenvolvimento humano, já que desde a proposta dos Parâmetros Curriculares Nacionais (BRASIL, 1997), tem um tratamento específico de conteúdo educacionais para Professores de Geografia. A compreensão e intervenção na realidade social agregam profissionais da área de Direito, e estabelece entre a Geografia e o Direito a atuação profissional deste último, especialmente em áreas rurais. Os levantamentos teóricos caminharam pelo art. 225 da atual Constituição Federal, uma âncora ao tratar o meio ambiente ecologicamente equilibrado, como expressão de bem de uso comum do povo. A metodologia bibliográfica entre o discurso teórico e a necessidade de alcançar o objetivo acadêmico, resultaram em um Direito Ambiental nas atividades de preservação da Natureza. Concluiu-se que, o Direito preserva a Natureza, mas também acolhe o desenvolvimento humano.
\end{abstract}

Palavras-chave: Direito Ambiental, Geografia, Pontal do Paranapanema.

ENVIRONMENTAL LAW AND GEOGRAPHY IN THE PARANAPANEMA PONTAL: MARABÁ PAULISTA AND PRESIDENT VENCESLAU-SP.

\begin{abstract}
The theme of Environmental Law and Geography of the Pontal do Paranapanema - SP has emerged in the same possession of human development, since since the proposal of the National Curricular Parameters (BRASIL, 1997), it has a specific treatment of educational content for Teachers of Geography. The understanding and intervention in the social reality add professionals from the area of Law, and establishes between Geography and Law the professional performance of the latter, especially in rural areas. Theoretical surveys went through art. 225 of the current Federal Constitution, an anchor in treating the ecologically balanced environment, as an expression of the common good of the people. The bibliographic methodology between the theoretical discourse and the need to reach the academic objective, resulted in an Environmental Law in the activities of preservation of Nature. It was concluded that the Law preserves Nature, but also welcomes human development.
\end{abstract}

Keywords: Environmental Law, Geography, Pontal do Paranapanema.

\section{INTRODUÇÃO}

O empenho pela temática, sobre o Direito Ambiental e a Geografia do Pontal do Paranapanema - SP no presente artigo, está desde a sugestão dos Parâmetros Curriculares Nacionais (BRASIL, 1997), que contém um processo exclusivo de teor educacionais, a profissionais com entendimento em Nível Superior no Curso de Geografia, assim apontados de Professores, uma vez que apresenta ferramentas eficazes para a abrangência e influência na realidade social que ao próprio período adicionam profissionais da ciência do Direito. Por meio dela; temos que 
compreender quanto diversas coletividades interagem com a forma da natureza no construir de seu lugar, as singularidades do espaço em que habituam-se, o que distingue e o aborda de diversos ambientes e, de tal modo, apanhar uma consciência profissional de analogias, que podese constituir entre a Geografia e o Direito na ação profissional deste último.

A possibilidade de esboços em destaque, para girar esse ambiente educativo um elemento respeitável em indagação, está na problematização sobre: os aspectos vinculados às modificações ambientais.

Contudo, o lugar e a região são analisados bem como, grandezas práticas resultantes das influências mútuas dentre o homem e a natureza. Atualmente, o conjunto de lugar, de tal modo quanto a de paisagem permanecem constituindo reavidas pelas novidades da Geografia, em uma inovação da dimensão. O lugar abandonou de ser meramente o espaço em que acontecem influência mútua dentre o homem e a natureza; para agrupar os aspectos peculiares que estabelecem ao lado com a materialidade dos lugares, e com as quais ao mesmo tempo interagem.

Assim, o presente artigo tem como escopo geral nesta indagação teórica, elevar um apoio de pesquisa bibliográfica que tem no art. 225 da Constituição Federal de 1988, uma âncora ao versar do meio ambiente ecologicamente equilibrado, como expressão de bem de uso comum do povo.

\section{METODOLOGIA}

Com esta tarefa, propõe-se conseguir um reforço à discussão sobre a díade: Geografia, e, Direito Ambiental. No acréscimo do conteúdo, a propósito, dos contornos dos conhecimentos da ciência, sobre o embasamento nas relações humanas e físicas, de modo explícita, clara, inteligível e funcional. Para a formulação do artigo virar individualizado, específico e inconfundível.

\section{DISCUSSÃO}

\section{1-A GEOGRAFIA E O DIREITO ENQUANTO EMPODERAMENTO DE CARACTERÍSTICA DE RELAÇÃO HUMANA:}

As obras acadêmicas, em contorno do entendimento da Geografia incidiu por disparidades e andamentos no tempo, provocando pensamentos caracterizados, emblemáticos, com conteúdo que aborda os elementos e metodologias do discorrer e perpetrar geográfico. De certa forma, esses pensamentos influenciaram e ainda influenciam muitas aprendizados de ensino atualmente.

Nesse sentido, ao reforço dado pelo autor Saquet (2011; p 8), em sua obra: concepções de geografia, espaço e território, envolvendo o ilustre "Milton Santos", o espaço necessita ser analisado como contexto:

conjunto de relações realizadas através de funções e formas apresentadas historicamente por processos tanto do passado como do presente. 0 espaço é resultado e condição dos processos sociais, elaboração amplamente difusa na geografia dos anos 1970-80 em países como a França, EUA e Brasil, pois era compreendido como uma categoria fundamental quando predominava a utilização de princípios do materialismo histórico e dialético.

O lugar e a região eram ininterruptamente vistos como extensões objetivas resultantes das interações entre o homem e a natureza. Presentemente, o conjunto de lugar, do mesmo modo quanto a de paisagem encontrar-se sendo readquiridas pela inovação da Geografia, em uma nova extensão. O lugar abandonou de ser somente o espaço em que acontecem interações entre o 
homem e a natureza para agrupar os aspectos peculiares que estabelecem ao lado com a materialidade dos lugares, e com as quais também interagem.

Continuando a ideia do autor a cima, Saquet $(2011 ; \mathrm{p}$ 8), que realça considerações, é possível compreender a distinção entre território e espaço;

[...] a utilização do território pelo povo cria o espaço"; imutável em seus limites e apresentando mudanças ao longo da história, o território antecede o espaço. Já o espaço geográfico é mais amplo e complexo, entendido como um sistema indissociável de sistemas de objetos e ações, em que a instância social é uma expressão concreta e histórica. O território é um conceito subjacente em sua elaboração teórico-metodológica e representa um dado fixo, delimitado, uma área.

Esse tipo de categorização é benéfica de maneira especial como se reflete em interferir em decisões respectivas a políticas públicas: verificadas questões ambientais são acatadas de atitude urbano, quanto saneamento, circulação, áreas verdes, patrimônio histórico; e outras são acatadas questões rurais, quanto os pertinentes aos recursos hídricos, conservação de áreas com vegetação natural, erosão, uso de agrotóxicos.

Em seguida, os esboços dos teores obrigatórios sobre a Geografia, é apropriado observar no "continuum" que se constitui na produção da informação de disparidade configurações de pautar e agregar as analogias das atividades de Geografia, que necessitam gerar aprendizagens significativas e funcionais, e também de qualidade.

É, ainda adequado, uma maneira favorável para realizar as atividades jurídicas que permitem o maior número de relações que constituem as estruturas de conhecimento de uma disciplina, o que para eterno e clássico "Milton Santos", a Geografia pode ser entendida como uma filosofia das metodologias, ao pretender o estudo das paisagens, territórios, lugares e regiões. A Geografia tem buscado um trabalho interdisciplinar, não lançando mão de outras fontes de informação.

Uma das qualidades principais da produção acadêmica da Geografia dos derradeiros tempos, foi o surgimento de enfoques que analisam as extensões subjetivas e, portanto, particulares dos indivíduos em coletividade.

Que a Geografia, não seja exclusivamente centralizada na definição do empirismo das paisagens, também não ajustada apenas pelo esclarecimento política e econômica do mundo; que trabalhe tanto as relações socioculturais da paisagem como os elementos físicos e biológicos que dela fazem parte, averiguando as múltiplas influência mútua entre eles colocados na constituição dos lugares e territórios. Fazendo então, buscar e explicar para compreender. (BRASIL, 1997)

Identificar e aferir os atos dos indivíduos em coletividade e suas decorrências em distantes espaços e tempos, de atitude que estabeleçam referenciais e possibilitam um conhecimento propositiva e reativa nas ações socioambientais locais. A ciência detém conhecimento, para empregar metodologias da Geografia, em que acarreta abrangência a respeito de a paisagem, o território e o lugar, seus procedimentos de construção, adaptar-se suas analogias, dificuldades e impossibilidades atuais.

1.1- O DIREITO, QUANTO TUTELA JURÍDICA AMBIENTAL:

O que se reafirma nesse andamento é a obrigação de acréscimo nessa ciência, coesos com ferramentas conceitual sobre o Homem, Natureza, Sociedade e as Leis de Proteção ao Meio Ambiente que alçou nas pesquisas de leituras dos autores que aqui constituíram de suma autoridade para a compreensão dos vínculos teóricos para a perfeição do discurso em busca do Direito em ação. 
Na noção pedagógica torna-se expressivo para Silva (2005) toda busca do fundamento do conceito de direito que ao longo da formação dos saberes é fundada pelos direitos do Homem àquilo que lhe pertencem, no que se refere às estratégias ou deveriam pertencer, ou dos quais nenhum homem pode ser despojado.

Para o autor em tela, a paisagem das ciências que emprega táticas num período democrático como é a do Brasil, bem como à claridade do que "[...] são os direitos compreendidos na própria Constituição Brasileira de 1988, permite dar uma justificação válida para o que determina o direito de cada cidadão. (SILVA, 2005, p.13)

Já, o Direito Ambiental tem como uma das suas inquietações agirem de feitio a prevenir os impactos na natureza.

A legislação ambiental brasileira, de forma plausível prioriza a preservação dos recursos naturais, na qual o desenvolvimento da sociedade deve ser de uma forma sustentável, em equilíbrio, atendendo as necessidades atuais, mas que não comprometa a possibilidade das gerações futuras de satisfazerem a suas próprias necessidades. (OJEDA; SIQUEIRA; PINTO 2013, p.3)

A Constituição Federal Brasileira possui um capítulo específico sobre meio ambiente (Capítulo VI), onde estabelece em seu Art. 225 que

Todos têm direito ao meio ambiente ecologicamente equilibrado, bem de uso comum do povo e essencial à sadia qualidade de vida, impondo-se ao Poder Público e à coletividade o dever de defendê-lo e preservá-lo para as presentes e futuras gerações. (OJEDA; SIQUEIRA; PINTO 2013, p.4)

Como se conclui da visão aqui publicada, a fundamental função deste trabalho pedagógico com o tema Geografia: Meio Ambiente e Direito é ainda um reforço para o entendimento acadêmico, para de tal modo, ficarem competentes para definirem e operarem na realidade socioambiental de um jeito empenhado em atuar como profissional, que apresenta em sua capacidade deveres e obrigações que é uma das capacidades do Direito como ciência da humanidade entre as analogias humanas.

A perspectiva ambiental proporciona ferramentas para que o indivíduo possa abranger dificuldades na sociedade e do mundo. Muitas das ações políticas, econômicas e sociais são permeadas por elementos absolutamente ligados à questão ambiental.

Os impactos ambientais atuais, incluem contextos constantes na meios de comunicação social e analisar oportuniza expandir o conhecimento sobre o assunto, de contorno a colaborar para o procedimento evolutivo e ampliação, o que solicita do Direito, em desempenho da questão provocada pela responsabilidade e pela concretização da preservação da Natureza.

Segundo Barbieri (2004), os recursos naturais são domínios e aparelhos originais ou elementares dos quais alguéns dependem. De tal modo, pode-se descrever que produzir é transformar ou modificar-se bens e serviços naturais para satisfação as indigências e os anseios humanos. Os recursos naturais, em regra cognominados Terra, nos textos de Economia, envolvem elementos ou partes do meio ambiente físico e biológico, como terra, plantas, animalejos, minérios e tudo o que possa ser benéfico e inteligível à produção da subsistência humana.

Do mesmo modo, a propósito de os solos arenosos do Pontal do Paranapanema, é

[...] encontrado o maior número de processos erosivos do estado de São Paulo (IPT, 1994) e, em municípios como Presidente Venceslau e Marabá Paulista, onde ocorrem solos da Formação Santo Anastácio, os processos erosivos são de grandes dimensões (Estado Geoecológico Fragilizado - F e 
Moderado Fragilizado - MF). A perda da fertilidade e a degradação de alguns setores desses municípios apontam para um início de processo de arenização dos solos. Associado aos processos erosivos e a ausência do filtro, proporcionado pelas matas ciliares aos corpos d'água, nestes municípios, ainda são encontrados os rios com maiores quantidades de sedimentos ou processos de assoreamento (Estado Geoecológico Fragilizado - F). Os tributários do rio Santo Anastácio, como o ribeirão Areia Dourada (Município de Marabá Paulista) ou os afluentes do ribeirão Claro (Presidente Venceslau), podem ser considerados os corpos d'água com maiores acumulações de sedimentos. (BOIN; OSCO, 2016, p.203)

Segundo os autores Boin e Osco (2016), os aspectos qualitativos proporcionam atividade modificada, bem como, confrontada às alterações acontecidas no meio ambiente. Um impacto ambiental positivo pode desdobrar por um breve espaço de período no tempo, como ao mesmo tempo, persistir por alongados anos. Por exemplo, a atividade de reflorestamento - que causa a preservação do solo, a fauna silvestre, os corpos d'água - amortece o efeito estufa, entre outros decorrências que promovem uma melhora na qualidade de vida para todos os seres vivos. Entretanto, os impactos negativos determinados pelas indústrias e diferentes segmentos, alcançam distintos recursos naturais danificando não só a qualidade de vida, como ainda, em determinados acontecimentos, a oportuna existência da mesma.

A capacidade de Boin e Osco (2016) no encerramento de suas qualificadoras sobre degradação ambiental mostrar-se que:

Os graves problemas ambientais que ocorrem desde o início do século passado no Pontal do Paranapanema - como a extinção da ora da fauna; a exaustão e erosão do solo; o assoreamento e a desperenização dos rios, a poluição das águas superficiais e subterrâneas -, que são causados pelas atividades humanas, nunca ameaçaram tanto a qualidade ambiental e a própria sobrevivência do homem nesse espaço geográfico como hoje. Esses fatos exigem providências urgentes para a minimização e/ou, solução desses problemas por meio do uso racional do espaço geográfico e dos recursos naturais por meio de medidas de planejamento e gestão ambiental-territorial. (BOIN; OSCO, 2016, p.204)

De tal maneira, como um direito, a preservação é definida, em nosso ordenamento jurídico. Assim como, dever do direito do cidadão - dever do Estado. É forçoso que se forme uma política efetiva, numa afinidade lógica e recíproca que estabelecendo uma sociedade de preservação ambiental - uma modalidade de qualidade de vida.

\section{CONCLUSÃO}

Aprofundar a informação sobre a aplicabilidade das normas jurídicas para ações, e a fundação das mesmas, apoiadas como competentes atenuantes dos impactos ambientais que possam vir a originar. Assim como, da sua fundação é um dos ícones das normas jurídicas brasileira. Este considera, as feições biológicos e ecológicos equilibrados relacionados a toda atividade humana que decorra a ser inserida, para precaver os impactos que decorram a ser determinados de feitio direta e indireta ao meio socioambiental.

As normas, não são apenas decretadas para permanecerem em uma superfície teórico: elas são formadas para proporcionar ocupação à coletividade humana em que aparecem. Assim, o 
função da lei está ligado a um desempenho articuladora de qualidades que admitem ou beneficiam um convívio saudável e serena dos sujeitos na coletividade de que fazem parte.

Com esse ajuste, o estudante de Direito tem a prerrogativa de explorar uma incomensurável rede de deveres e obrigações, para apoderar-se, da ciência jurídica na preservação do Meio Ambiente. Adentro, da existência da lei, associada com o conhecimento jurídico, em um modo de resolver casos concretos.

Enfim, não se pode falar na existência da lei dissociada da sociedade. Mostra-se necessário estudar o Direito como fato que se processa na sociedade e nela interfere, também recebendo desta influências diversas. Há que se falar na existência de um vínculo do Direito com a estrutura social em que ele se insere, de sorte que temos no direito um exemplo de fato social.

\section{REFERÊNCIAS}

BOIN, Marcos Norberto; OSCO, Lucas Prado. Geoecologia da paisagem do Pontal do Paranapanema/SP: o olhar da paisagem ao lonto do século XX. Entre-Lugar, Dourado, MS, ano 6, n.12, 1.semestre, 2016. Universidade Federal da Grande Dourados, p.189-207.

BRASIL. Constituição Federal da República Brasileira 1988. Disponível em: < http://www.planalto.gov.br/ccivil_03/constituicao/constituicaocompilado.htm>. Acesso em: 10 abr. 2017.

BRASIL. Secretaria de Educação Fundamental. Parâmetros curriculares nacionais: Geografia / Secretaria de Educação Fundamental. Brasília: MEC/SEF, 1998. Disponível em: < http://portal.mec.gov.br/seb/arquivos/pdf/geografia.pdf> Acesso em: 10 abr. 2017.

FUSHIMI, Melina. Vulnerabilidade ambiental aos processos erosivos lineares de parte dos municípios de Marabá Paulista-SP e Presidente Epitácio-SP. Presidente Prudente, 2016. Universidade Estadual Paulista - Unesp-Faculdade de Ciências e Tecnologia - FCT. Câmpus de Presidente Prudente. Programa de Pós-graduação em Geografia, Tese de Doutorado.

MOCELLIN, Giani Motin. Conscientização da importância da mata ciliar no ensino fundamental na região rural do município de Colombo-PR. Medianeira: Universidade Tecnológica Federal do Paraná, 2014. Diretoria de Pesquisa e Pós-Graduação. Especialização em Ensino de Ciências.

OJEDA, Katiane da Cruz, SIQUEIRA, Francioly Marcos Batista, PINTO, Adrianna Amorim de Sousa. Diagnóstico ambiental da área de preservação permanente no alto curso do córrego do São Gonçalo, Cuiabá-MT. Instituição Federal de Educação, Ciência e Tecnologia de Mato Grosso. IV Congresso Brasileiro de Gestão Ambiental. Salvador/BA - 25 a 28/11/2013. IBEAS - Instituto Brasileiro de Estudos Ambientais.

SANTOS, Adriana Maria Silva. Direito e Política: Uma Relação na Sociedade. Âmbito Juridico. Disponível em: <http://www.ambitojuridico.com.br/site/index.php?n_link=revista_artigos_leitura\&artigo_id=1916>. Acesso em: 10 abr. 2017.

SAQUET, Marcos Aurélio; SILVA, Sueli Santos da. Milton Santos: Concepções de Geografia, Espaço e Território. ISSN 1981-9021 - Geo UERJ - Ano 10, v.2, n.18, 2o semestre de 2008. P. p.1-19. 
Disponível

em:

$<$ http://www.epublicacoes.uerj.br/index.php/geouerj/article/viewFile/1389/1179>. Acesso em: 10 abr. 2017.

SILVA, Caio Mário da. Instituições de direito civil. v.1. Rio de Janeiro: Forense, 2005.

TORRES, Leonardo Araújo; TORRES, Rodrigo Araújo. Direito Ambiental brasileiro: surgimento, conceito e hermenêutica . Revista Jus Navigandi, ISSN 1518-4862, Teresina, ano 17, n. 3248, 23 maio 2012. Disponível em: <https://jus.com.br/artigos/21836>. Acesso em: 10 abr. 2017. 